\title{
Posttraumatic Stress Disorder Among U.S. Army Reserve Vietnam and Vietnam-Era Veterans
}

\author{
Robert H. Stretch \\ Department of Military Psychiatry \\ Walter Reed Army Institute of Research \\ Walter Reed Army Medical Center \\ Washington, DC
}

\begin{abstract}
Results are presented from an epidemiologic investigation of posttraumatic stress disorder (PTSD) among Vietnam and Vietnam-era veterans. Analysis of questionnaire data collected in the Spring of 1982 from 935 randomly selected Vietnam and Vietnam-era veterans assigned to U.S. Army Reserve troop units nationwide reveals a PTSD rate for Vietnam veteran reservists of $10.9 \%$, which is midrange between estimates for civilian (18\%-54\%) and active duty Army (5.1\%) Vietnam veterans. Results suggest that the quality of social support received during Vietnam duty and the first year back may serve to either moderate or exacerbate PTSD symptomatology associated with combat experience.
\end{abstract}

It has been estimated that $18 \%-54 \%$ of civilian Vietnam veterans are suffering from posttraumatic stress disorder (PTSD; Disabled American Veterans Association, 1980; Harris \& Associates, 1980). Stretch (in press) found a much lower rate $(5.1 \%)$ among active duty Army veterans as well as evidence that social support on return from Vietnam may have an even greater impact on the attenuation of PTSD than combat experience.

Another group of Vietnam veterans that has not been studied consists of Army reservists. These veterans are likely to have received more positive support resulting from their continued military affiliation than did veterans who left the military and should have a lower prevalence of PTSD than civilians, but not as low as that for veterans still on active duty.

The present study tests the hypothesis that PTSD is influenced by combat experience, social support experiences during and after service in Vietnam, and the time period served in Vietnam (pre- or postTet 1968). The time period is considered important due to problems of low morale, increased antiwar sentiment, and drug abuse that occurred after the Tet Offensive in 1968 (Renner, 1973). The Army neuropsychiatric casualty rate also increased sharply in 1969 and remained high until the bulk of U.S. forces left Vietnam in mid-1972 (Datel, 1976).

The opinions expressed herein are those of the author and do not necessarily reflect the views of the Department of the Army or the Department of Defense.

Requests for reprints and an extended report of this study should be sent to Robert $H$. Stretch, who is now at the Science and Technology Laboratory, U.S. Army Natick Research and Development Command, Natick, Massachusetts 01760 .

\section{Method}

A stratified random sample of 2,000 male Vietnam and Vietnam-era veterans was obtained from the U.S. Army Reserve. Groups 1 and 2 consisted of 500 Vietnam veterans who had been released from active duty in 1968 and 500 released in 1971. Groups 3 and 4 consisted of 500 Vietnam-era veterans released from active duty in 1968 and 500 released in 1971.

Along with a cover letter and appropriate informed consent forms, each veteran was sent a questionnaire, the Vietnam-Era Veterans Adjustment Survey (VEVAS). The VEVAS is a reliable instrument that provides information on demographics, attitudes and opinions about the war, combat experience, and social support and psychosocial health during and after service in Vietnam (see Stretch, in press, for scale items, reliabilities, and scoring procedures). All participation in the study was voluntary, and responses were protected by Confidentiality Certificate MH-82-14 issued by the National Institute of Mental Health. Questionnaires from 86 Vietnam and 76 Vietnam-era veterans were returned undelivered. Responses were received from 667 Vietnam and 258 Vietnam-era veterans for response rates of $73 \%$ and $28 \%$, respectively. The low response rate for Vietnam-era veterans is perhaps due to their lack of any emotional stake in the study and is similar to the rate (33\%) among active duty Vietnam-era veterans in Phase 1 of the project (Stretch, in press).

The average age of the Vietnam veterans was 36.7 years old. These veterans were mostly white $(84 \%)$, married $(83 \%)$, well-educated $(84 \%$ have some college education), volunteered for Army service $(61 \%)$, and were on active duty an average 42 months. Officers composed $44 \%$ of the sample. 
The Vietnam-era veterans were also mostly white $(95 \%)$, married $(83 \%)$, well-educated $(84 \%$ have some college education), and volunteered for Army service $(68 \%)$. Officers composed $35 \%$ of the sample. These veterans differed, however, from the Vietnam veterans in that they were younger $(M=35.8$ years old), $t(915)=3.28, p<.01$, and had less active duty service $(M=24.4$ years), $\iota(916)=8.27, p<.01$.

\section{Results}

A significantly greater percentage of Vietnam (53\%) than Vietnam-era veterans (44\%) stated they would be willing to fight in a similar future war, $\chi^{2}(4, N=891)=7.44, p<.05$. More than $80 \%$ of the veterans in both samples felt their military service had helped them become better persons, but considerably fewer Vietnam veterans $(57 \%)$ felt their service in Vietnam was beneficial.

Responses to key items in the VEVAs indicate that 73 Vietnam veterans $(10.9 \%)$ and 4 Vietnam-era veterans $(1.5 \%)$ were currently experiencing symptoms of PTSD, $\chi^{2}(4, N=925)=7.18, p<.01$. As predicted, this prevalence of PTSD symptoms among reserve Vietnam veterans is lower than estimates for civilians, but significantly higher than that of active duty Vietnam veterans $(5.1 \%), \chi^{2}(4$, $N=908)=7.18, p<.01$.

Results of a stepwise multiple regression analysis on PTSD symptoms revealed significant main effects for rank, combat experience, and social support during and after service in Vietnam. The greatest proportion of explained variance is accounted for by combat experience $(12 \%)$ and social support on return from Vietnam (12\%). Enlisted veterans had significantly higher levels of PTSD symptoms than did officers, $F(1,597)=10.37, p<.01$.

Veterans with high combat experience had higher levels of PTSD symptoms than did veterans with low combat experience, $F(1,597)=15.92, p<.01$. A similar effect was observed for social support on return from Vietnam, $F(1,597)=75.10, p<.01$.

Although no significant effect was found for the time period variable, the effect was in the predicted direction of higher levels of PTSD symptoms for veterans who served in the late, rather than the early, part of the war.

\section{Discussion}

The present study provides support for the hypothesis that PTSD is affected not only by combat experience but also by the quality of social support received during and particularly after service in Vietnam. Social support appears to play an important role in determining whether the veteran is able to successfully cope with PTSD symptoms. Subsequent phases of the project are currently underway to compare these results from studies of active duty and reserve Army veterans with those of prior-service civilian veterans and active duty Army nurses. Continued research is needed to expand our knowledge of the etiology of PTSD among Vietnam veterans.

\section{References}

Datel, W. E. (1976). A summary of source data in military psychiatric epidemiology (Report No. A 021 265). Alexandria, VA: Defense Documentation Center.

Disabled American Veterans Association. (1980, January). Forgotten warriors: America's Vietnam-era veterans. Washington, DC: Author.

Harris, L., \& Associates. (1980). Myths and realities: A study of attitudes toward Vietnam Era veterans (Submitted by the Veterans Administration to the Committee on Veterans Affairs, U.S. Senate, Senate Committee Print No. 29). Washington, DC: U.S. Government Printing Office.

Renner, J. A. (1973). The changing patterns of problems in Vietnam. Comprehensive Psychiatry, 14, 169-181.

Stretch, R. (in press). Incidence and etiology of post-traumatic stress disorder among active duty Army personnel. Journal of Applied Social Psychology.

Received November 16, 1984 Revision received April 19, 1985 